\title{
Деконструкция Aegyptiaca Romana: историографические трансформации и постановка проблемы ${ }^{1}$
}

\author{
Чисталев М.С. \\ Нижегородский государственный университет им. Н.И. Лобачевского, \\ Россия, 603950, г. Нижний Новгород, пр. Гагарина, д. 23 \\ E-mail: marcus7@mail.ru
}

\begin{abstract}
Аннотация. В статье анализируются подходы и концепции исследований, посвященных проблемам изучения Aegyptiaca Romana в римском обществе, в зарубежном антиковедении. Отмечается, что религиозная интерпретация египетских и египтизированных предметов и артефактов длительное время являлась доминирующей парадигмой. Вплоть до 1970-х годов основной проблемой всех таких исследований являлось игнорирование контекста использования объектов, взаимосвязи формы и материала, специфики стилистического выражения (особенно применительно к объектам, произведенным в Италии), а также отказ принять во внимание возможность наличия более широкого спектра интерпретаций культовых образов. В то же время отличительной особенностью изысканий, опубликованных в последние годы, является смещение акцентов в трактовке Aegyptiaca Romana в новую крайность, а именно - полное неприятие религиозного контекста, что представляется слабо аргументированным и необоснованным.
\end{abstract}

Ключевые слова: Древний Рим, Египет, Aegyptiaca Romana, восприятие иноземной культуры.

Для цитирования: Чисталев М.C. 2021. Деконструкция Aegyptiaca Romana: историографические трансформации и постановка проблемы. Via in tempore. История Политология. 48 (4): 749-754. DOI: $10.52575 / 2687-0967-2021-48-4-749-754$.

\section{Deconstruction of Aegyptiaca Romana: historiographical transformations and problem statement}

\author{
Mark S. Chistalev \\ Lobachevsky State University of Nizhny Novgorod, \\ 23 Gagarin Ave., Nizhny Novgorod, 603950, Russia \\ E-mail: marcus7@mail.ru
}

\begin{abstract}
The article analyzes the approaches and concepts of research devoted to the problems of studying Aegyptiaca Romana in Roman society in foreign classical studies. In the historiography of Aegyptiaca Romana, the religious interpretation, mainly associated with the cult of Isis, has long been the dominant paradigm. Only in the mid-1990s and early 2000s did the first works appear in which there is a rejection of the dogmatic attitude to search for a religious context with an emphasis on general cultural interpretation. In general, the most important result of the research carried out to date is the understanding that the one-sided interpretation of Aegyptiaca Romana as closely related to the religious context was erroneous, and the study of the ideas about Aegyptiaca Romana should be based on the entire set of the historical relations between Egypt and Rome, it is necessary to take into account the context, the relationship of form and material, the specifics of stylistic expression, and also to consider the possibility of a wider range of interpretations of cultic images, but without shifting to a new extreme of complete rejection of the religious context.
\end{abstract}

${ }^{1}$ Работа выполнена при финансовой поддержке РНФ, проект № 20-18-00374 «Имперское Средиземноморье: модели, дискурсы и практики империализма от Античности до раннего Нового времени». 
Keywords: Ancient Rome, Egypt, Aegyptiaca Romana, perception of foreign culture.

For citation: Chistalev M.S. 2021. Deconstruction of Aegyptiaca Romana: historiographical transformations and problem statement. Via in tempore. History and political science. 48 (4): 749-754 (in Russian). DOI: 10.52575/2687-0967-2021-48-4-749-754.

\section{Введение}

В историографии Aegyptiaca Romana религиозная интерпретация, преимущественно связанная с культом Исиды, длительное время являлась доминирующей парадигмой. Когда во второй половине XIX в. на территории Италии были обнаружены многочисленные египетские и египтизированные предметы и артефакты, они были автоматически отнесены к категории религиозных предметов, связанных с египетскими культами [Lafaye, 1883]. Не менее значимым является тот факт, что большая часть первых исследователей Aegyptiaca были египтологами, что не могло не сказаться на характеристике находок, сделанных в Исеуме в Помпеях, римском Iseum Campense [Hülsen, 1903] и в Беневенто, как имеющих религиозную основу.

\section{Результаты и их обсуждение}

Несмотря на появление специальных исследований, посвященных археологическим находкам на территории Рима и Италии [Hülsen, 1903], лишь с середины XX в. наблюдается новый импульс в изучении распространения эллинизированных египетских культов.

Появление работ Ж. Леклана и М. Дж. Вермасерена по изучению отношения к египетской религии в римском мире положили начало серии ÉPRO - Études préliminaires aux religions orientales dans l'Empire romain, которая в последующем превратилась в серию RGRW - Religions in the Graeco-Roman World, в которой изучаются социальные и культурные особенности греко-римских религиозных воззрений, в том числе их взаимодействие с ранним христианством, иудаизмом и исламом, на значительном историческом этапе, охватывающем период от 400 г. до н. э. и вплоть до 700 г. н. э.

Особо следует сказать об опубликованной в 1964 г. работе Венсана Тран Там Тинха [Tinh V. Tran Tam, 1964], посвященной культу Исиды, отчасти сохранившей даже в наше время свою значимость в вопросах исследования Aegyptiaca в Помпеях. Будучи одним из первых авторов, кто изучал распространение культа Исиды в Италии в тесной взаимосвязи с объектами материальной культуры, имеющими отношение к Египту, В. Тран Там Тинх оказал существенное влияние на классификацию различных изображений и предметов с египетской тематикой как имеющих отношение к религиозной деятельности. Применительно к находкам из Помпей причиной установления религиозной трактовки в качестве основополагающей является открытие в 1769 г. и последующие раскопки храма Исиды. Его хорошая сохранность, указывающая на быстрое восстановление после землетрясения 62 г. н. э., а также месторасположение позволяли сделать вывод о том, что город был центром культа египетской богини в Кампании, а это, в свою очередь, косвенно подтверждало значительные масштабы распространения культа Исиды в регионе.

В целом В. Тран Там Тинху удалось каталогизировать множество объектов, найденных в Помпеях, которые он связывал с культом Исиды ${ }^{2}$. В него вошли: настенные росписи, рельефы, статуи, небольшие статуэтки и бюсты, украшения, граффити, систры ${ }^{3}$ и т. д. Все они так или иначе стилистически были связаны с Египтом или с образом Исиды. Однако работа В. Тран Там Тинха имела существенный недостаток: автор абсолютно

${ }^{2}$ Сам автор пишет, что все эти предметы «красноречиво подчеркивают религиозность (в поклонении Исиде - М.Ч.) жителей города» [Tinh V. Tran Tam, 1964, p. 6].

${ }^{3}$ В перечне В. Тран Там Тинха дан 21 систр, найденный в Помпеях в различных частях города. 
игнорировал не только контекст, в котором данные объекты были обнаружены, но и их функциональное предназначение.

1970-е годы стали определяющими для изучения Aegyptiaca Romana, поскольку именно в этот период появились сразу две монографии по египетским и египтизированным артефактам, найденным в Италии: работа Мишеля Малеза «Inventaire préliminaire des documents égyptiens découverts en Italie» [Malaise, 1972] и монография Анны Руле «Тhе Egyptian and Egyptianising monuments of imperial Rome» [Roullet, 1972]. Систематизация и интерпретация М. Малеза включала в себя находки, сделанные только на территории Италии, в то время как А. Руле расширила границы, включив в каталог артефакты, которые были найдены в провинциях империи. Оба исследования, опубликованные в серии ÉPRO, настолько безапелляционно относили Aegyptiaca Romana к египетским религиозным культам, что стали основой для многих последующих изысканий, не позволив учесть критику такого подхода, которая в виде осторожных сомнений впервые была высказана К. Шефолдом [Schefold, 1952] еще в 1952 г. В своих публикациях по римской настенной живописи он отмечал, что не все владельцы домов, в которых была обнаружена символика, связанная с культом Исиды, были последователями ее религиозного культа ${ }^{4}$.

Основная проблема всех вышеперечисленных исследований заключается не столько в однобоком подходе к трактовке Aegyptiaca, сколько в игнорировании контекста использования объектов, взаимосвязи формы и материала, специфики стилистического выражения (особенно применительно к объектам, сделанным в Италии), а также отказе принять во внимание возможность наличия более широкого спектра интерпретаций культовых образов.

Монография М. Малэза стала отправной точкой для исследования M. Де Boc [De Vos, 1980], появившегося почти десятилетие спустя и изданного в уже упомянутой нами серии ÉPRO. Впервые Aegyptiaca рассматривалась с новой концептуальной позиции, где главная роль отводилась не египетским религиозным культам, а культурным процессам, происходившим в римском обществе. Однако обозначив римские, а также помпейские фрески и мозаику «египтоманией» в названии своей работы, М. Де Вос не только не раскрывает специфику применения данного термина, но и обходит стороной анализ генезиса самого явления.

Лишь в 1994 г. в связи с проведением выставки «Египтомания: Египет в западном искусстве 1730-1930» и выходом каталога с аналогичным названием [Egyptomania, 1994] редакторам, в частности Жану-Марселю Юмберу [Humbert, 1994] ${ }^{5}$, впервые удалось дать четкое обоснование применению термина «египтомания». Раскрывая масштаб европейского увлечения «египетскими мотивами», Ж.-М. Юмбер обращается не только к объектам архитектуры, интерьерам, скульптуре, живописи, памятникам декоративно-прикладного искусства относительно недавнего европейского прошлого, но и к процессам, происходившим в Римской империи. На различных примерах он демонстрирует актуальность феномена египтомании на разных этапах развития европейского общества, благодаря его способности к трансформации в зависимости от исторических обстоятельств. Заслугой автора также является первое логически выстроенное обоснование принципиальных различий между оригинальными египетскими объектами и египтизированными образцами, для которых, как верно отметил Ж.-М. Юмбер, всегда существует как минимум еще один контекст, не имеющий ничего общего с оригинальным египетским значением: «символический, эзотерический, политический или коммерческий» [Egyptomania, 1994, p. 25 ].

В этой связи не случайно, что именно середина 1990-х - начало 2000-х гг. становится новым этапом интереса к взаимоотношениям между Египтом и Римом. Пол Мэйбум [Meyboom, 1995] стал одним из первых авторов, отказавшихся от догматической установ-

${ }^{4}$ «Gewiss können nicht alle Bewohner der Häuser mit Isissymbolen Anhänger dieser Religion gewesen sein» [Schefold, 1952, S. 58].

${ }^{5}$ Следует отметить еще несколько работ французского египтолога, посвященных теме: [Humbert, 1989; L'Égyptomanie à l'épreuve de l'archéologie, 1996; Imhotep Today, 2017]. 
ки на поиски религиозного контекста в Нильских сценах на примере Нильской мозаики Палестрины, сделав акцент на общекультурной интерпретации. Он приходит к выводу о том, что символическое значение Нильских сцен определяется их экзотическим характером, в котором очень сложно найти религиозный подтекст [Mеyboom, 1995, p. 84].

Среди профильных статей этого периода отдельно следует выделить работу M. Золднер [Söldner, 2000]. Автор отвергает тезис М. Де Вос о наличии египтомании в римском обществе, равно как и отказывается от религиозной интерпретации Aegyptiaca в правлении Августа. Опираясь на исследование Пауля Цанкера [Zanker, 1987], М. Золднер настаивает на политическом подтексте египетской тематики, использовавшейся в качестве элементов пропаганды.

$\mathrm{He}$ менее значимым является масштабное исследование Мигеля Верслюйса [Versluys, 2002], в котором ему удалось не только составить самый полный каталог всех известных на момент публикации Нильских сцен, но и убедительно доказать необходимость отказа от давно изжившей себя традиции идентифицировать все египетские сюжеты в частных домах и общественных сооружениях римлян как религиозные. Он указывает на то, что истинное значение Нильских сцен определяется исключительно контекстом его использования, выделяя при этом три различные категории: религиозную, декоративную и политическую. В то же время ранние Нильские сцены он предлагает выделить в качестве отдельного направления, обозначив их Нильскими пейзажами. Что немаловажно, М. Верслюйс отказывается принять аргументацию М. Де Вос и трактовать масштабное распространение Aegyptiaca в римском обществе как римскую египтоманию [Versluys, 2002, p. 14].

В общем русле рассмотрения специфики нового подхода, подразумевающего отказ от поиска исключительно религиозной подоплеки в интерпретации египетских предметов, найденных на территории Италии, находится и исследование М. Сьютнем-Барленд [Swetnam-Burland, 2007]. По ее мнению, найденные предметы должны быть сначала достоверно отнесены к Aegyptiaca Romana, и лишь затем следует предпринимать попытки по интерпретации находок. Причем автор делает акцент на том, что религиозная трактовка в большинстве случаев является не более чем одним из возможных вариантов. В своей статье М. Сьютнем-Барленд предлагает отказаться от прямолинейного поиска смысловых аналогий в интерпретации Aegyptiaca Romana с тем, как использовались эти предметы в самом Египте. На примере Aegyptiaca из Исеума в Помпеях она пытается обосновать свою точку зрения и указывает на «общесмысловую» [Swetnam-Burland, 2007, p. 134] направленность египетских и египтизированных артефактов, называя это явление «смысловым диалогом» [Swetnam-Burland, 2007, p. 134].

Другой подход был предложен Пенелопой Дэвис [Davies, 2011], настаивающей на рассмотрении Aegyptiaca Romana в более широких культурных границах путем сопоставления их с греческой стилистикой в Риме.

Одними из последних комплексных исследований, подытоживающих свершившийся в последние десятилетия сдвиг парадигмы религиозной интерпретации Aegyptiaca, является совместная работа Джузеппины Виттоцци и Мигеля Верслюйса «La terra del Nilo sulle sponde del Tevere» [Vittozzi, Versluys, 2013], в которой все объекты египетской материальной культуры помещены в римский контекст, а также неопубликованная диссертация Евы Мол [Mol, 2015]. Акцентируя свое внимание на находках, сделанных в Помпеях, Е. Мол предлагает полное переосмысление Aegyptiaca Romana исключительно в рамках римского культурного контекста без оглядки на египетскую традицию. Из этого следует, что автор не только отделяет египетские объекты от египтизированных, но и фактически отказывается от признания за последними какой бы то ни было взаимосвязи с египетскими оригиналами.

Центральной работой, посвященной изучению Aegyptiaca Romana, увидевшей свет в течение последних двух лет, является монография Кэтлин Бэррет [Barrett, 2019]. Свое исследование автор ограничивает египетскими образами в садах помпейских домовладений, при этом в русле современных историографических тенденций полностью отказывается от рели- 
гиозной трактовки Aegyptiaca Romana. По мнению автора, египетские мозаики и фрески были далеки от простой документальной фиксации традиционного образа жизни в долине Нила, создавая сложное переплетение египетских реалий и interpretatio Romana, дополненного продолжающимся процессом формирования римлянами образа другого (на примере египтян) посредством дихотомии свой - чужой. Однако, как подчеркивает К. Бэррет, чуждые римлянам образы постепенно становились частью римской материальной культуры, которые преобразовывали пространство римского дома в «микрокосм империи» (microcosm of empire).

Следует отдельно отметить, что в отличие от западной историографической традиции, которая начиная с конца XX в. и до настоящего времени ставит знак равенства между понятиями «египтомания» и «египетский ренессанс» ${ }^{6}$, мы не склонны делать столь поспешные выводы. Безусловно, римское увлечение египетской культурой, начавшееся в правление Августа, после завоевания Египта и начала становления Рима как мировой державы, стало уникальным явлением, к которому уже на ранних этапах (в конце I в. до н. э.) уместно применить термин «египетский ренессанс». Однако понятие «египтомания» предусматривает не любое обращение к египетской тематике, а естественную ${ }^{7}$ популяризацию топосов египетской культуры, предполагающую представление о Египте исключительно (или преимущественно) в позитивном ключе, чего в конце I в. до н. э. мы не наблюдаем. Пропагандистские постулаты поэзии эпохи Августа отчасти получили распространение и в материальной культуре: здесь будет уместно вспомнить об обелисках, установленных на спйне Circus Maximus и в Солярии на Марсовом поле, а также о росписях Aula Isiaca, датируемых 25-20 гг. до н. э. Само по себе активное вовлечение египетской тематики в римскую действительность является показателем активного интереса к Египту со стороны римлян, но в правление Августа это явление было лишь частью процесса становления римского имперского сознания, подчеркивающего достижения принцепса. Именно поэтому для характеристики всплеска интереса к египетской культуре в правление Августа уместно использование понятия «египетский ренессанс», а начиная со 2-ой четверти I в. н. э. можно говорить о постепенной трансформации явления в египтоманию.

\section{Выводы}

В целом при изучении Aegyptiaca Romana следует четко придерживаться подхода, сложившегося в последние десятилетия в историографии, который подразумевает отказ от безоговорочной религиозной трактовки египетских и египтизированных предметов и артефактов без надлежащего исследования того контекста, в котором этот предмет бытовал. Важно отметить, что вплоть до настоящего времени, несмотря на значительное количество исследований, среди объектов Aegyptiaca Romana нельзя выделить ни одну группу предметов, которая не вызывала бы определенных споров в мировой историографии. Именно поэтому переосмысление контекстуализации египетских и египтизированных объектов должно проводиться, не впадая в крайности, свойственные как наиболее ранним этапам исследования Aegyptiaca Romana, так и современным деконструктивистским подходам.

\section{Referenses}

1. Barrett C.E. 2019. Domesticating Empire: Egyptian Landscapes in Pompeian Gardens. Oxford, Oxford University Press, 445.

2. Curl S. 2005. The Egyptian revival: ancient Egypt as the inspiration for the design motifs in the west. New York, Routledge, 572.

\footnotetext{
${ }^{6}$ Подробнее см.: [Curran, 1996; Curl, 2005; Curran, 2007; Imhotep Today, 2017].

${ }^{7}$ В данном контексте под естественной популяризацией мы понимаем процесс, не связанный с искусственным продвижением образов Египта, в том числе с помощью различных инструментов имперской пропаганды.
} 
3. Curran B.A. 1996. Review of J.M. Humbert, M. Pantazzi, C. Ziegler (eds.), Egyptomania: Egypt in western art, 1730-1930 (1994). In: The Art Bulletin. Vol. 78.4: 739-745.

4. Curran B.A. 2007. The Egyptian renaissance: the afterlife of ancient Egypt in early modern Italy. Chicago, The University of Chicago Press, 431.

5. Davies P.J.E. 2011. Aegyptiaca in Rome: adventus and romanitas. In: Cultural identity in the ancient Mediterranean. Ed. E. Gruen. Los Angeles, Getty Research Institute: 354-370.

6. De Vos M. 1980. L'egittomania in pitture e mosaici romano-campani della prima età imperiale. Leiden, Brill, 107.

7. Egyptomania: Egypt in Western art, 1730-1930. Ed. J.M. Humbert, M. Pantazzi, C. Ziegler. Paris, Réunion des musées nationaux, 1994.

8. Hülsen C. 1903. Porticus Divorum und Serapeum im Marsfelde. In: Mitteilungen des Kaiserlich Deutschen Archaeologischen Instituts. Bd. XVIII: 17-57.

9. Humbert J.M. 1989. L'Egyptomanie dans l'art occidental. Courbevoie, ACR Edition, 336.

10. Imhotep Today: Egyptianizing architecture. Ed. J.M. Humbert, C. Price. New York, Routledge, 2017.

11. L'Égyptomanie à l'épreuve de l'archéologie. Ed. J.M. Humbert. Paris, Musée du Louvre, 1996.

12. Lafaye G. 1883. Histoire du culte des divinités d'Alexandrie Sérapis, Isis, Harpocrate et Anubis hors de l'Égypte depuis les origines jusqu'a la naissance de l'école Néo-Platonicienne. Paris, Thorin, 342.

13. Malaise M. 1972. Inventaire préliminare des documents égyptiens découverts en Italie. Leiden, Brill, 207.

14. Meyboom P.G.P. 1995. The Nile Mosaic of Palestrina: Early Evidence of Egyptian Religion in Italy. Leiden, Brill, 409.

15. Mol E.M. 2015. Egypt in material and mind: the use and perception of Aegyptiaca in Roman domestic contexts of Pompeii. PhD Diss. Universiteit Leiden, 522. Brill, 184.

16. Roullet A. 1972. The Egyptian and Egyptianizing Monuments of Imperial Rome. Leiden,

17. Schefold K. 1952. Pompejanische Malerei: Sinn und Ideengeschichte. Basel, B. Schwabe, 207.

18. Söldner M. 2000. Ägyptenrezeption im augusteischen Rom. In: Antike Welt. Zeitschrift für. Archäologie und Kulturgeschichte. Bd. 31: 383-393.

19. Swetnam-Burland M. 2007. Egyptian Objects, Roman Contexts: A Taste for Aegyptiaca in Italy. In: Nile into Tiber. Egypt in the Roman World. Ed. L. Bricault, M.J. Versluys, P.G.P. Meyboom. Leiden: $113-136$.

20. Tinh V. Tran Tam. 1964. Essai sur le culte d'Isis à Pompéi. Paris, E. de Boccard, 206.

21. Versluys M.J. 2002. Aegyptiaca Romana: Nilotic Scenes and the Roman Views of Egypt. Leiden, Brill, 509.

22. Vittozzi G.C., Versluys M.J. 2013. La terra del Nilo sulle sponde del Tevere. Roma, Aracne, 313.

23. Zanker P. 1987. Augustus und die Macht der Bilder. Munich, C.H. Beck, 333.

Конфликт интересов: о потенциальном конфликте интересов не сообщалось.

Conflict of interest: no potential conflict of interest related to this article was reported.

\section{ИНФОРМАЦИЯ ОБ АВТОРЕ}

Чисталев Марк Сергеевич, кандидат исторических наук, научный сотрудник научноисследовательской лаборатории кафедры истории древнего мира и средних веков Института международных отношений и мировой истории Нижегородского государственного университета им. Н.И. Лобачевского, г. Нижний Новгород, Россия

\section{INFORMATION ABOUT THE AUTHOR}

Mark S. Chistalev, Candidate of Historical Sciences, Researcher at the Research Laboratory of the Department of the History of the Ancient World and the Middle Ages, Institute of International Relations and World History, Nizhny Novgorod State University named after N.I. Lobachevsky, Nizhny Novgorod, Russia 